Article

\title{
The Microstructure and Mechanical Properties of Poplar Catkin Fibers Evaluated by Atomic Force Microscope (AFM) and Nanoindentation
}

\author{
Yan $W u^{1,2}$, Xinyu Wu ${ }^{1,2}$, Tianlin Shi ${ }^{1,2,3}$, Hong Chen ${ }^{1,2}$, Hankun Wang ${ }^{3,4, *}$, Meng Sun ${ }^{1,2}$ and \\ Jilei Zhang ${ }^{5, *}$ \\ 1 College of Furnishings and Industrial Design, Nanjing Forestry University, Nanjing 210037, China; \\ wuyan@njfu.edu.cn (Y.W.); aprilwu2019@163.com (X.W.); shitianlin188@163.com (T.S.); \\ chenhong@njfu.edu.cn (H.C.); summerjasmines@foxmail.com (M.S.) \\ 2 Co-Innovation Center of Efficient Processing and Utilization of Forest Resources, Nanjing Forestry \\ University, Nanjing 210037, China \\ 3 Department of Biomaterials, International Center for Bamboo and Rattan, Beijing 100102, China \\ 4 DepaSFA and Beijing Co-built Key Laboratory of Bamboo and Rattan Science \& Technology, State Forestry \\ Administration, Beijing 100102, China \\ 5 Department of Sustainable Bioproducts, Mississippi State University, Mississippi State, MS 39762, USA \\ * Correspondence: wanghankun@icbr.ac.cn (H.W.); jz27@msstate.edu (J.Z.)
}

Received: 12 September 2019; Accepted: 22 October 2019; Published: 23 October 2019

\begin{abstract}
In this study, the microstructure and mechanical properties of poplar (Populus tomentosa) catkin fibers (PCFs) were investigated using field emission scanning electron microscope, atomic force microscopy (AFM), X-ray diffraction, and nanoindentation methods. Experimental results indicated that PCFs had a thin-wall cell structure with a large cell lumen and the hollow part of the cell wall took up 80 percent of the whole cell wall. The average diameters of the fiber and cell lumen, and the cell wall thickness were 5.2, 4.2, and $0.5 \mu \mathrm{m}$, respectively. The crystallinity of fibers was $32 \%$. The AFM images showed that the orientation of microfibrils in cell walls was irregular and their average diameters were almost between 20.6-20.8 nm after being treated with 2 and 5 wt.\% potassium hydroxide $(\mathrm{KOH})$, respectively. According to the test of nanoindentation, the average longitudinal-reduced elastic modulus of the PCF S 2 layer was $5.28 \mathrm{GPa}$ and the hardness was $0.25 \mathrm{GPa}$.
\end{abstract}

Keywords: poplar catkin fiber; microstructure; cellulose nano-fibrils

\section{Introduction}

Nanocellulose can be widely used in many fields, such as those of papermaking, composite materials, medical, purification and filtration, chemical, and information. In particular, the addition of nanocellulose can greatly enhance the physical properties of pulp. Nanocellulose has a high biomass compatibility, high specific surface area, and other excellent properties, so it can be added to the composite as a reinforcing agent. Nanocellulose is a stable colloid, so it can be used as a drug carrier in the pharmaceutical industry. Therefore, the study of natural cellulose and its derivatives has received increasing attention [1,2]. Cellulose nanofibrils (CNFs) have a length of several microns and a diameter that is around $15 \mathrm{~nm}$ [3]. Because of their unique supramolecular structure and morphology, CNFs have excellent mechanical, optical, and small-molecular physical barrier properties [4]. Therefore, CNFs have broad potential applications in biomaterials, medicine, information, and other industries [5,6]. 
Poplar (Populus tomentosa) catkin fiber (PCF) is a cotton-like catkin fiber covering the seeds of white poplar trees [7]. Poplar is a kind of fast-growing tree species with a short growth cycle and low price. It is mainly concentrated in the northeast, north China, and northwest areas. The total area of poplar forest in China exceeds $70,000 \mathrm{~km}^{2}$, and it increases year by year. Each poplar tree can harvest about $25 \mathrm{~kg}$ of catkins. The tassel fiber is mainly composed of cellulose and hemicellulose, as well as lignin, with a thin cell wall and large lumen [8]. During the period from April to June each year, PCFs float in the air, causing great trouble for the environment and residents' health. Zhang et al. [9] focused on poplar (Populus tomentosa) catkin fiber as a new resource for bioethanol production via enzymatic hydrolysis. Yin et al. [10] studied the water absorption and oil absorption of poplar catkins. They studied how to inhibit the production of PCFs, but not how to utilize them. There are few studies on the microstructure and mechanical properties of PCFs.

In recent years, microscopic imaging and spectral characterization methods have been used in nanostructure and chemical composition analyses of cell walls of plant fibers like wood fibers [11-16], bamboo fibers [17-22], and cotton fibers [23,24]. Chen et al. [25] characterized the aggregation of microfibrils in the cross-section of thin-wall cells using the atomic force microscopy (AFM) technique. Xiao et al. [26] and Hao et al. [24] investigated the cell wall layer structure of kapok fibers using X-ray diffraction (XRD) and Fourier transform infrared spectroscopy (FT-IR) through formulating an efficient organic solvent system to isolate cellulose from lignin and concluded that both kapok and cotton fibers had similar multi-wall layer structures. Fernandes et al. [27] investigated the nanostructures of spruce fibers using a series of spectroscopic techniques, such as small angle neutron ray scanning (SANS) and wide-angle X-ray scattering (WAXS).

Oliver and Pharr. [28] established an improved technique of determining the hardness and elastic modulus of wood fibers using load-displacement sensing indentation. Micromechanical testing in combination with spectral analysis technology is an effective way of studying the microstructure and properties of plant fibers $[29,30]$ because of the development and application of microscopic mechanical characterization methods, such as single fiber stretching and nanoindentation technologies. In addition, Himmel et al. [31] pointed out that biodegradable barriers of biomass affect the bioconversion cost of wood fiber raw materials. A more comprehensive and in-depth understanding of the barriers will help break down the biodegradable barrier of plant fibers more effectively.

Cell walls are thin, flexible layers ( 0.1 to 1.0 microns) of complex polysaccharides, lignin, and a few structural proteins that form a three-dimensional network structure of fibers, playing an important role in plant growth, cell differentiation, and plant support [8]. The cell wall of PCFs has three layers, which are the primary wall, secondary wall, and epidermal layer, respectively. The thickness of the primary wall and epidermal layer is relatively thin, and the secondary wall is relatively thick [9]. Cellulose is the main component of plant cell walls and provides the tensile strength. The cellulose in plants is mainly in the form of small microfibers, which is the basic unit of a cellulose molecule [8]. In plant cells, lignin, the second most abundant macromolecular substance, is found in the gaps in the structure formed by cellulose. The effect of lignin enhances the toughness of the xylem and thus enhances the mechanical strength of plants [10]. The microfibril arrangements of primary walls and the epidermis have been shown to be similar. PCFs have a lower lignin content and higher cellulose content, undoubtedly breaking down the biomass degradation barrier to a large extent [11,31], which is of great benefit for improving the conversion rate of CNF. Therefore, this study investigated the microstructure and nanomechanical properties of PCFs using field emission scanning electron microscopy (FE-SEM), atomic force microscopy (AFM), X-ray diffraction (XRD), infrared spectrometer (FT-IR), and nanoindentation methods. The results of studying the structure and cell wall mechanical property of PCF may play a vital role in the use of PCF in high value-added fields, such as nanocellulose. 


\section{Materials and Methods}

\subsection{Materials}

The PCFs were collected from poplar trees in Beijing, China, during April 2016. The poplar fiber in this experiment was collected by an automatic collection device composed of a fan and filter. The poplar catkin fibers were carefully isolated from the wind-dispersal seeds after air-drying and kept in sealed plastic bags for further use. Commercial chloroform $\left(\mathrm{CHCl}_{3}\right)$, sodium chlorite $\left(\mathrm{NaClO}_{2}\right)$, glacial acetic acid $\left(\mathrm{CH}_{3} \mathrm{COOH}\right)$, potassium hydroxide $(\mathrm{KOH})$, ethanol $\left(\mathrm{CH}_{3} \mathrm{CH}_{2} \mathrm{OH}\right)$, and deionized (DI) water were all purchased from Sigma-Aldrich.

\subsection{Pretreatments}

The pretreatment started with grinding PCFs, followed by dewaxing, delignification, and hemicellulose removal [31-36]. The dewaxing treatment started with ground PCFs being added into a $100 \mathrm{~mL}$ chloroform beaker, followed by stirring of the mixture in a $70{ }^{\circ} \mathrm{C}$ water bath for $20 \mathrm{~min}$ and then washing of the mixture with deionized water and a pressure filter to produce a neutral $\mathrm{pH}$ value. Finally, the mixture was stored in a condition chamber at $4{ }^{\circ} \mathrm{C}$ and relative humidity of $40 \% \pm 2 \%$. The dewaxed fibers were treated with a $0.5 \mathrm{wt} . \%$ concentration of acidified sodium chlorite ( $\mathrm{pH}$ was adjusted to 4-5 with glacial acetic acid) for $2 \mathrm{~h}$ to remove lignin. The delignified PCFs were dipped in 2 and $5 \mathrm{wt}$.\% concentrations of sodium hydroxide $(\mathrm{KOH})$ solutions at $90{ }^{\circ} \mathrm{C}$ for $12 \mathrm{~h}$, respectively, to remove hemicellulose, and the catkin fibers were then washed with deionizer (DI) water thoroughly to remove $\mathrm{KOH}$ residual until the $\mathrm{pH}$ value of 7 was reached. The fiber mass to alkali weight ratio was 1:20. The obtained fiber suspensions were frozen in liquid nitrogen first, followed by drying for $24 \mathrm{~h}$ in a freeze dryer $[37,38]$.

\subsection{Specific Surface Area}

The specific area of a PCF was measured through recording the adsorption-desorption of the PCF using the $\mathrm{N}_{2}$ adsorption method at $77 \mathrm{~K}$.

\subsection{XRD}

The crystallinity index of untreated PCF powders was characterized using an Xpert'Pro Parna Co. X-ray diffractometer (The Netherlands).

\subsection{Micro-Morphology}

FE-SEM images of PCFs were obtained using XL30 FEI (USA) to characterize their micro-morphology and wall cavity ratio. A PCF was glued on a carrier using conductive adhesive for FE-SEM imaging of its longitudinal direction. The cross-section of a PCF was made by placing the fiber vertically in a slender container. Following this, the container was frozen in liquid nitrogen, cut crossly, and placed on a carrier with conductive adhesive, and vacuum gold spraying was carried out to enhance the electrical conductivity.

\section{6. $A F M$}

Compared to an optical microscope, the atomic force microscope (AFM) has more varieties for different working environments and a higher resolution for obtaining images like amplitude, height, and phase images. The amplitude is the image formed through vibrating the probe on the sample surface. The height reflects the smoothness of a sample surface. The phase image reflects the viscosity and hardness of a sample, assisting accurate analysis of the height images.

The cell wall microfibrils' morphology and modulus of PCFs were analyzed using an AFM instrument (Icon, Bruker Co, Billerica, MA, USA) equipped with an $8 \mathrm{~nm}$ radius probe and $125 \mathrm{~nm}$ long cantilever beam. The instrument modes were set to tapping mode and peak force quantitative 
nanomechanics (PQNM) mode, respectively. PQNM is an extension of the peak force tapping mode, where the vertical motion of the cantilever oscillates far below its resonant frequency. Each tapping event during the imaging is actually an action of the probe indenting into the surface of the materials [9]. Silicon OTESPA probes with a nominal spring constant of $12-103 \mathrm{~N} \mathrm{~m}^{-1}$ and tip radius of $10-20 \mathrm{~nm}$ were used. The vibration frequency, scanning speed, and force constant of the instrument were set to $320 \mathrm{kHz}, 42 \mathrm{~N} / \mathrm{m}$, and $1 \mathrm{~Hz}$, respectively. The size and distribution of microfibrils' aggregation in the inner and outer walls of a fiber cell wall can be accurately measured using the phase imaging mode. The diameters of aggregated microfibrils were measured using an AFM-related image processing software (NanoScope Analysis 4.0, Bruker Co, Billerica, MA, USA). Ten microfibril aggregates were measured for each $\mathrm{KOH}$ solution-treated sample, and the average diameter value was calculated. AFM can be used to obtain not only in situ images, but also modulus images, using PQNM mode. In addition, the corresponding 3D modulus image can be obtained through AFM analysis software of NanoScope Analysis 4.0 [22]. A single fiber was observed directly, without being embedded in epoxy resin for measuring properties in its longitudinal direction, but the fiber was chemically treated.

\subsection{FT-IR}

The hemicellulose-removed and -untreated poplar catkin fibers were dried first and then ground to powders, and the fiber powder (1 part in weight) was then mixed to potassium bromide $(\mathrm{KBr})$ (100 parts in weight). Chemical compositions and functional groups of these poplar catkin fibers were analyzed using Bruker's FT-IR spectrometer (Avance 300, Bruker Co, Billerica, MA, USA). The transmission mode was selected. The frequency of spectral scanning was 200 times, and the range of spectral acquisition was $650 \sim 4000 \mathrm{~cm}^{-1}$.

\subsection{In Situ Nanoindentation}

The sample for studying the transverse section of a PCF was prepared through wetting, freeze-drying, and embedding a PCF in epoxy resin, followed by cutting the fiber-embedded block crossly to the size of $100 \mu \mathrm{m}$ wide $\times 100 \mu \mathrm{m}$ deep using the ultra-thin slicing machine. The nanoindentation on fiber cell walls was performed using an in situ imaging nanoindenter (Triboindenter, Hysitron, Eden Prairie, MN, USA) with the load-controlled mode set to a peak load of $250 \mu N$. The cell walls of a PCF were selected first using a light microscope and then raster-scanned with a Berkovich tip with its radius being less than $100 \mathrm{~nm}$. Thirty valid indents were made on the 5-8 cell walls selected. The reduced elastic modulus and hardness values were calculated in reference to the method developed by Oliver and Pharr. [28]. The environmental temperature of the instrument chamber was kept at $23{ }^{\circ} \mathrm{C}$ and the relative humidity was kept at $40 \% \pm 2 \%$.

\section{Results and Discussion}

\subsection{Specific Surface Area}

Figure 1 illustrated that the adsorption capacity of nitrogen increased rapidly first, then slowly increased, and finally increased rapidly as the relative pressure increased, indicating a typical S-type isotherm. As usual, the sudden increases of nitrogen adsorption at the high-pressure end indicated the existence of mesopores and macropores on the surfaces, which is the result of multi-layer adsorption on the solid uniform surfaces. However, the results of the $\mathrm{N}_{2}$ adsorption and desorption test showed that the average pore size of PCFs was larger than $20 \mathrm{~nm}$, and there was no hysteresis ring in the middle and high-pressure region, indicating that there were no micro-pores in PCFs. The $\mathrm{N}_{2}$ adsorption capacity of PCFs was $5.2 \mathrm{~cm}^{3} / \mathrm{g}$, and the specific surface area of PCFs, which was calculated by using the Brunauer, Emmett, Telter (BET) method was $5.2 \mathrm{~m}^{2} / \mathrm{g}$. 


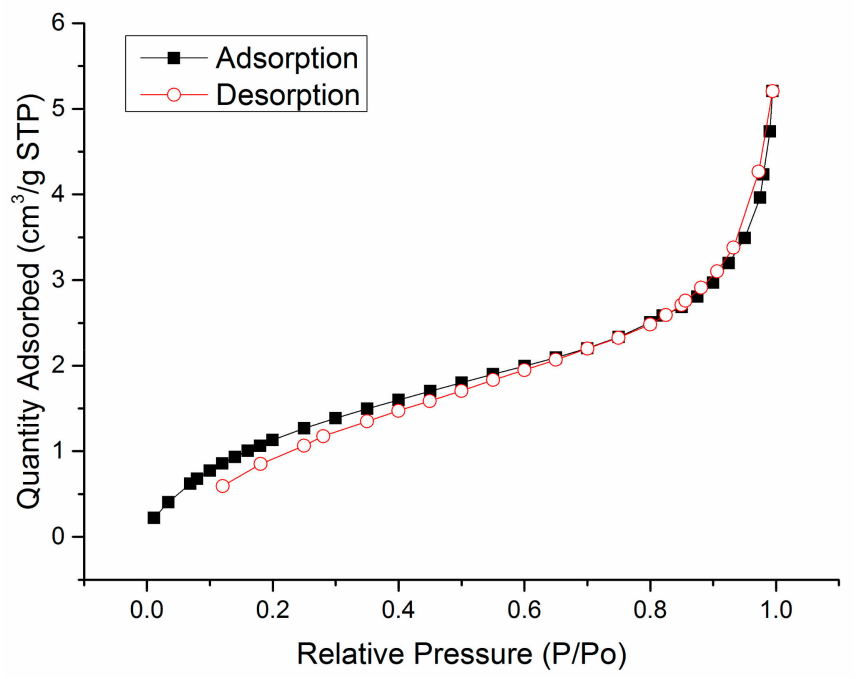

Figure 1. $\mathrm{N}_{2}$ adsorption and desorption curves recorded for poplar catkin fibers.

\subsection{Crystallinity Analysis}

Figure 2 showed that characteristic peaks of the cellulose I crystal plane (110) and cellulose I structure (200) appeared at $16^{\circ}$ and $22^{\circ}$, respectively [34]. The crystallinity was calculated based on the formula, crystallinity $=\left[\left(I_{002}-I_{a m}\right) / I_{002}\right] \times 100 \%$, where $I_{002}$ and $I_{a m}$ represent the diffraction intensity at $22^{\circ}$ and $18^{\circ}$, respectively, using the Segal method [39]. The intensity at $18^{\circ}$ corresponds to the minimum diffraction intensity in the amorphous region of cellulose. The crystallinity of PCFs was $32 \%$, which is lower than the one (56\%) of cotton fibers [34], the one (36\%) of kapok fibers [26], and also the one $(68.9 \%)$ of bamboo [40-43], respectively. Compared with the amorphous region, cotton fibers and kapok fibers are more difficult to separate and dilate. Therefore, the low crystallinity made the energy consumption of PCFs for the preparation of nano cellulose lower than that of the cotton fibers and kapok fibers.

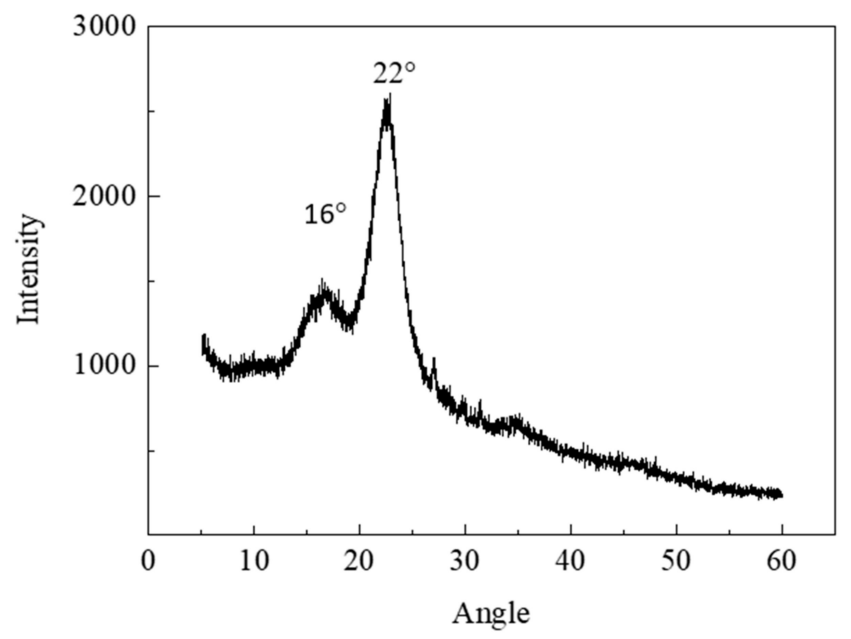

Figure 2. X-ray diffraction pattern of untreated poplar catkin fibers.

\subsection{Microstructure of PCFs}

The surface morphology of untreated PCFs (Figure 3A,B) showed that PCFs had a long, thin wall, and smooth surface structure with no twist and winding between fibers, indicating similar microstructures to wood and cotton fibers. The surface of treated PCFs (Figure 3C) was uneven because PCFs were the seed fiber of poplar with waxy materials on the surface, after dewaxing the fiber bundles and microfibril aggregates were exposed and the surface became rough. The cross-sections of treated 
PCFs (Figure 3D) were circular or oval shapes, the cell walls were thin and had serrated edges, and the cavity was large. The results measured by NanoScope image analysis software indicated that the average outer diameter, wall cavity diameter, and wall thickness of PCFs were 5.2, 4.2, and $0.5 \mu \mathrm{m}$, respectively; the ratio of the wall to cavity was $25 \%$; and the hollowness was as high as $80 \%$. These results were consistent with those of natural fibers, such as wood and cotton fibers [42]. The PCFs had the characteristics of a thin wall and cavity, and good hygroscopicity, benefiting from the high specific surface area. The moisture regained in the standard state was about $18 \%$, and the moisture absorption rate was twice as high as that of other textile fibers. The insets of Figure $3 C, D$ show that the microfibril arrangement of PCF cell walls was tight.
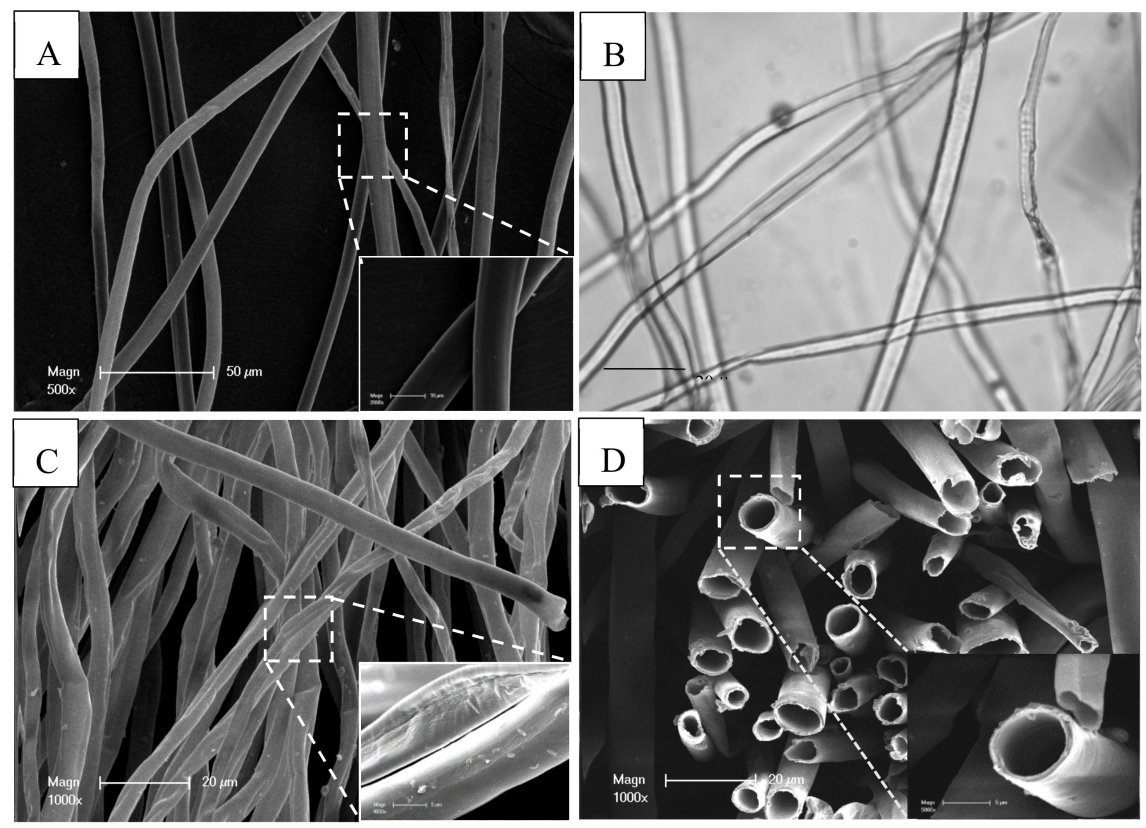

Figure 3. SEM and optical microscope images for poplar catkin fibers ((A) and (B) longitudinal surface before dewaxing; (C) longitudinal surface after dewaxing; (D) cross-section after dewaxing; the insets in $\mathrm{C}$ and $\mathrm{D}$ are large magnification images).

\subsection{AFM Analysis}

The AFM height image of untreated PCFs (Figure 4) indicated that there was a close-packed uneven layer of materials on fiber surfaces, confirming the existence of a waxy layer on PCF surfaces.
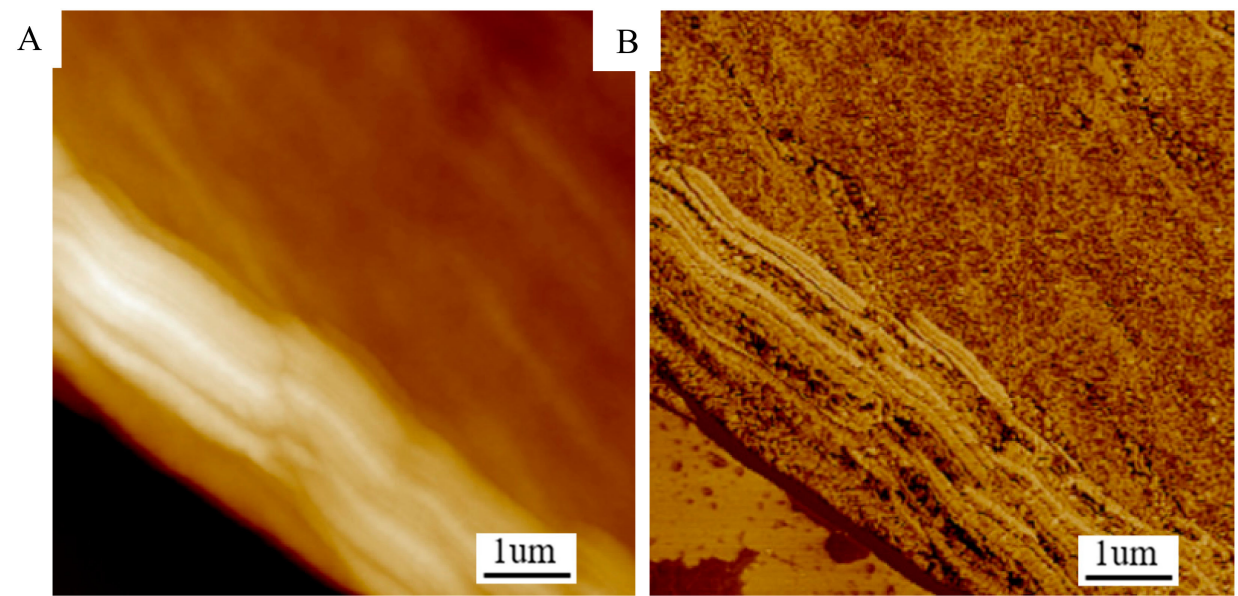

Figure 4. Atomic force microscopy (AFM) micrograph of the longitudinal surface of a poplar catkin fiber ((A) height map; (B) phase diagram). 
AFM was used to observe the microscopic appearance of PCF surfaces after chemical pretreatment. In Figure 5, he height image is shown on the left (Figure 5A) and the phase image is displayed on the right (Figure 5B). It can be seen from the figure that the surface of PCF after dewaxing treatment was composed of several irregular and uneven shaped materials, which related to the smooth waxy layer on the surface of PCF being exposed after chemical pretreatment.
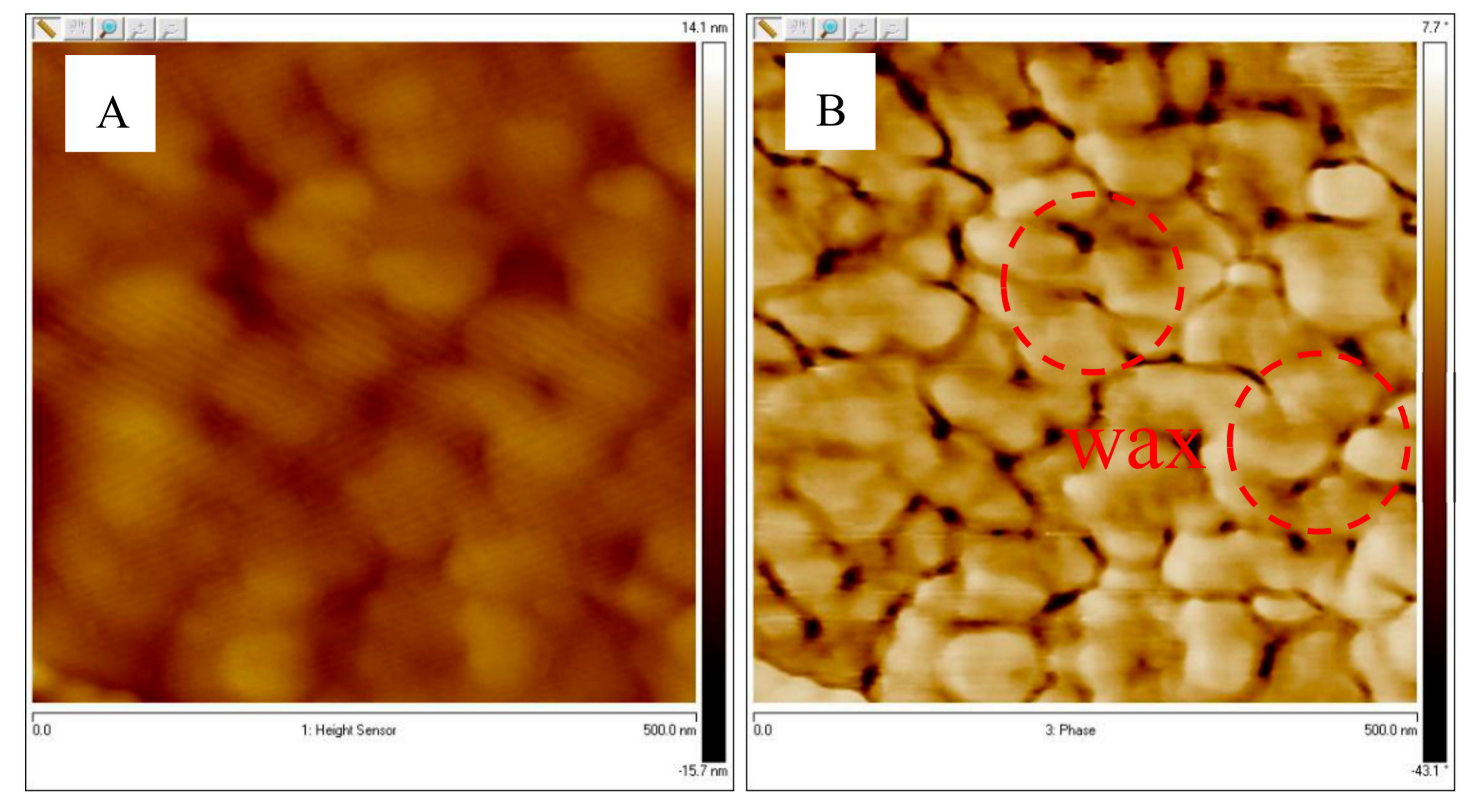

Figure 5. AFM images of the longitudinal surface of a poplar catkin fiber after chemical pretreatment ((A) height image, (B) phase image).

As can be seen from Figure 6, after dewaxing and treating PCFs with 2 wt.\% KOH solution for $12 \mathrm{~h}$, the arrangement of microfilaments on the cell wall surface of PCFs could be clearly observed in the height image. The disordered arrangement of the outer filaments on the cell wall showed the distribution characteristics of microfilaments in the $S_{1}$ layer of PCF. The disordered and irregular arrangements of microfibrils observed on PCFs were consistent with those observed by Yu et al. [44] on bamboo fiber cell walls using AFM. Chen et al. [18] concluded that the surface roughness of bamboo fibers increased with an increasing sodium hydroxide $(\mathrm{NaOH})$ concentration from $6 \%$ to $10 \%$. In the phase image, because the matrix was much less elastic and stiff than the microfilaments, the bright parts represented the cellulose microfilaments, and the spaces between the non-cellulose polysaccharide matrix and the microfilaments were darker. Image processing software (NanoScope 8.15 Analysis) was used to measure the size of microfilament aggregates. In order to make the data authentic and reliable, 10 pieces of PCFs were measured in the scanning images at different positions. Finally, the average value was obtained and the size of microfilament aggregates was $20.8 \mathrm{~nm}$ after being treated with $2 \mathrm{wt}$. $\%$ $\mathrm{KOH}$ solution for $12 \mathrm{~h}$. After dewaxing treatment, the characteristic peaks of aliphatic substances still existed at 2923 and $1738 \mathrm{~cm}^{-1}$, respectively. The dewaxing process of PCFs requires further discussion in order to obtain a clearer arrangement and more accurate morphological information on microfibrils.

After dewaxing and treatment with $5 \mathrm{wt} \% \mathrm{KOH}$ solution for $12 \mathrm{~h}$, the arrangement of microfilaments in the cell wall was observed in Figure 7 by AFM. Compared with the sample images of $2 \mathrm{wt}$ \% $\mathrm{KOH}$ solution treatment, the arrangement of microfilaments was almost completely observed, indicating that hemicellulose was basically removed and microfilaments were arranged in irregular layers. According to statistics obtained by the software, the size of microfilament aggregates was $20.6 \mathrm{~nm}$ after being treated with $5 \mathrm{wt}$.\% $\mathrm{KOH}$ solution for $12 \mathrm{~h}$. Comparing the size of microfilament after treatment with 2 wt.\% $\mathrm{KOH}$ solution, no difference was found between the two conditions, indicating that the alkali treatment in this study had little effect on the size of microfilaments. 
The partial removal of hemicellulose using the $\mathrm{KOH}$ solution with different concentrations of 2 and $5 \mathrm{wt} . \%$ might have contributed to the rougher surface of PCFs, resulting in the microfibrils being easily aggregated $[15,45]$. Figure 8 A,B indicated that the cross-section of a PCF was an oval shape, and the cell wall had a uniform thickness.
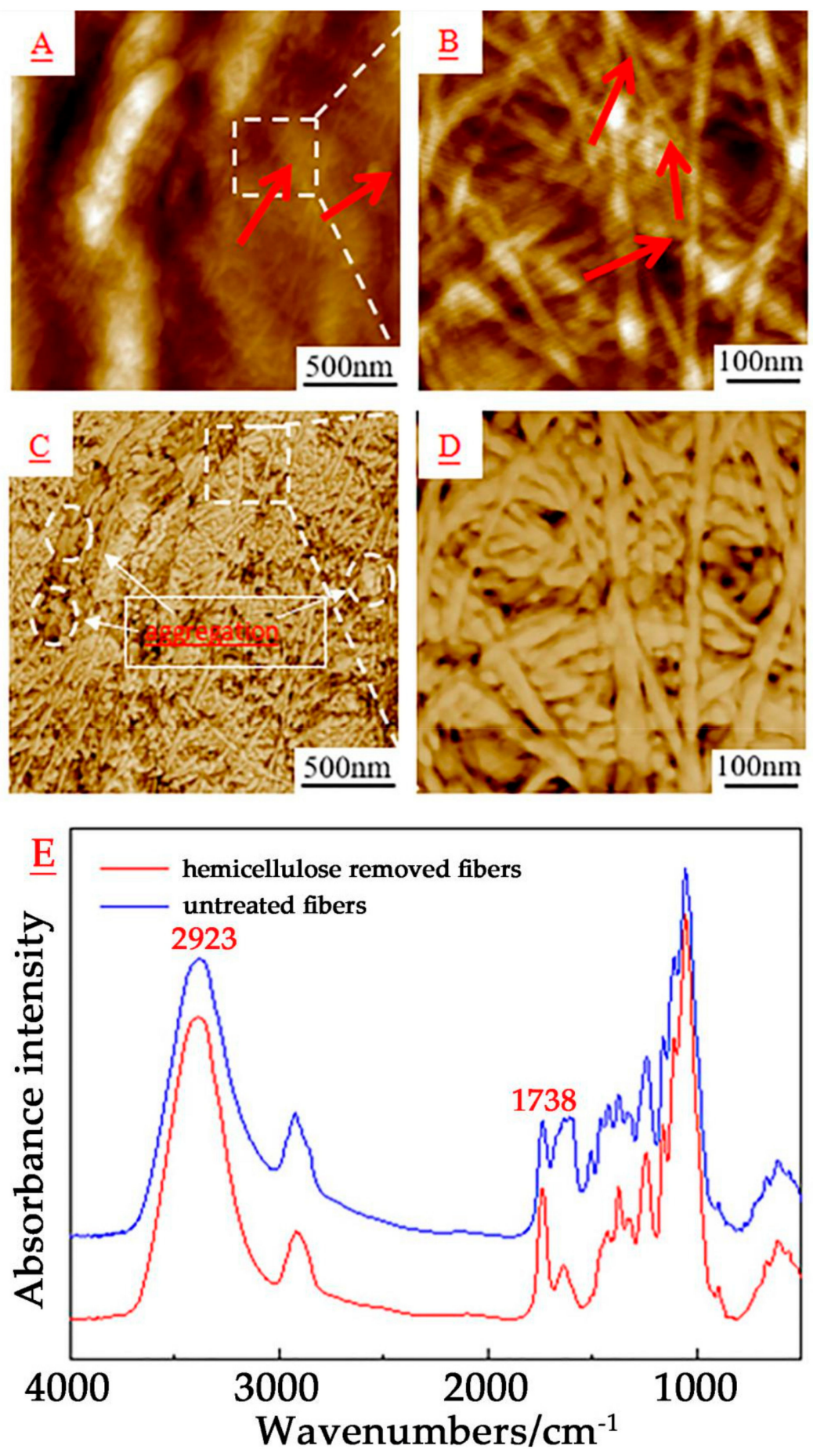

Figure 6. AFM images of the longitudinal surface of microfibrils arrangement of poplar catkin fibers treated with 2 wt.\% potassium hydroxide $(\mathrm{KOH})$ solution: $(\mathbf{A}, \mathbf{B})$ height images; $(\mathbf{C}, \mathbf{D})$ phase images; (E) FT-IR spectroscopy of untreated fibers and hemicellulose-removed fibers. 

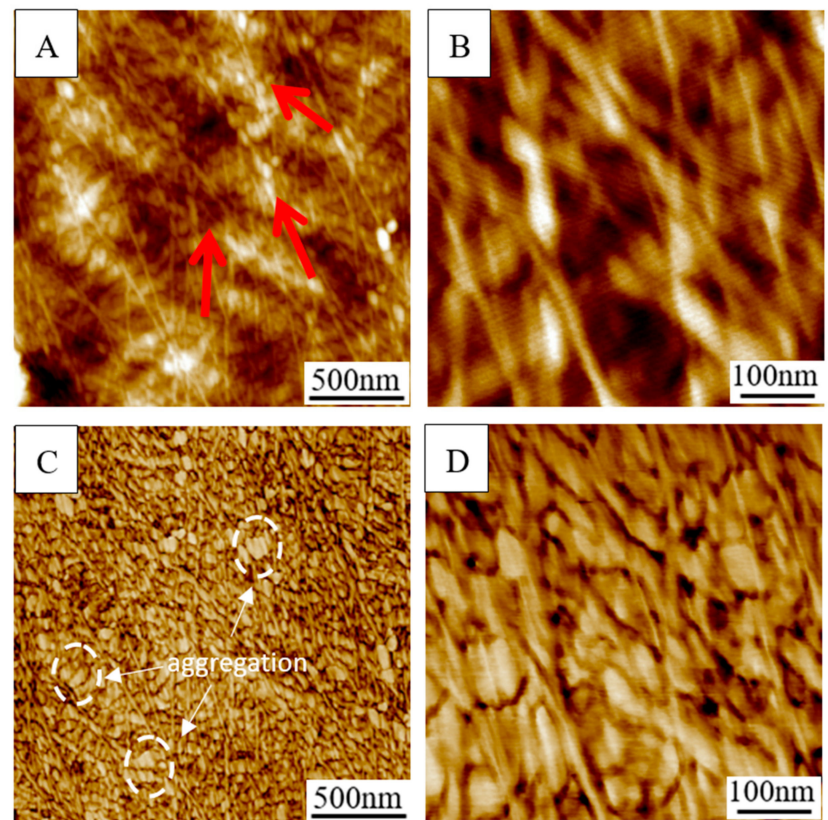

Figure 7. AFM images of the longitudinal surface of microfibrils arrangement of poplar catkin fibers treated with 5 wt.\% $\mathrm{KOH}$ solution: (A,B) height images; (C,D) phase images.
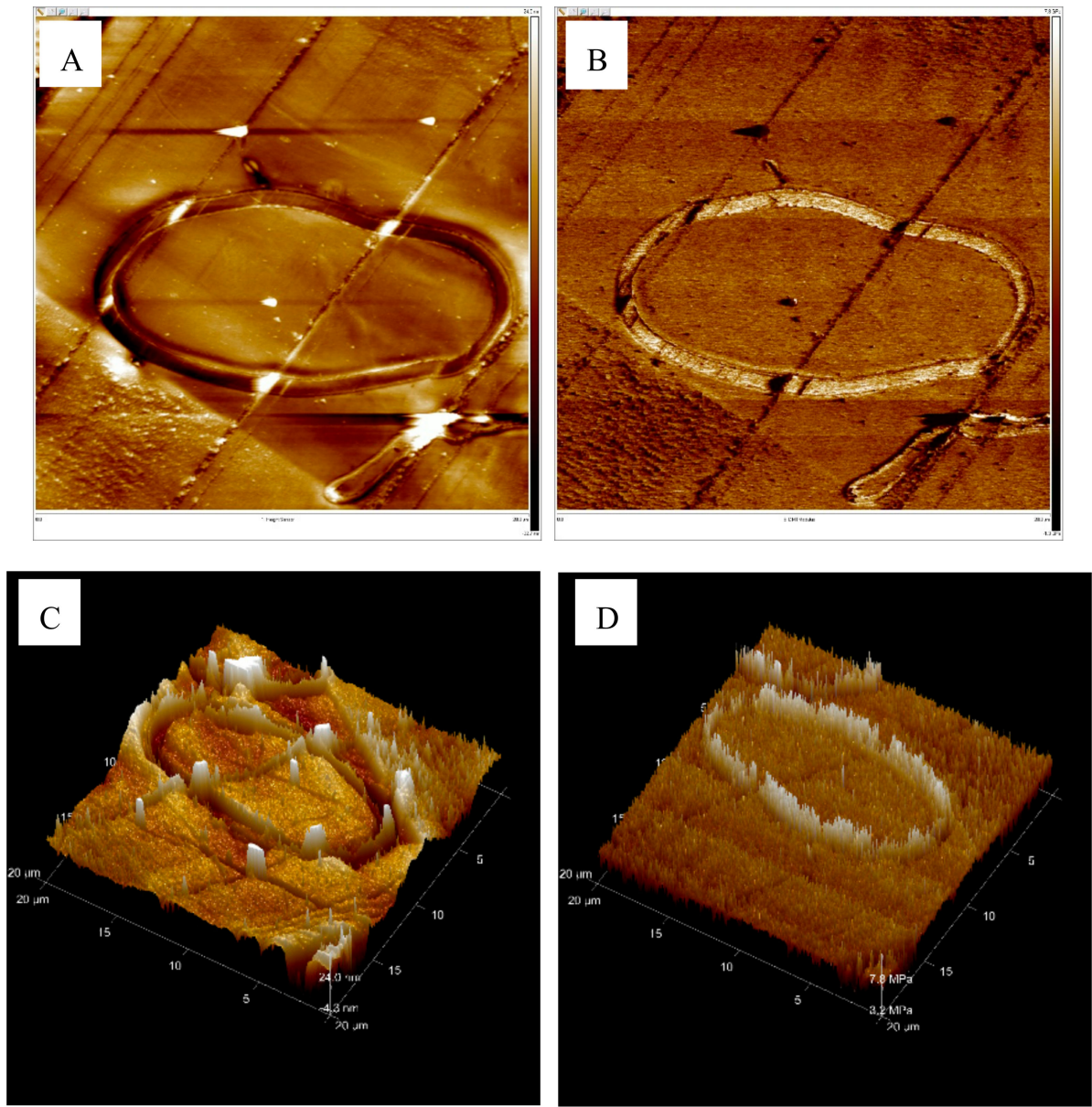

Figure 8. AFM observation of the cell wall modulus of a poplar catkin fiber (cross-section; size of $20 \mu \mathrm{m} \times 20 \mu \mathrm{m}$, (A) height image; (B) modulus image; (C) 3D height image; (D) 3D modulus image). 
Figures 8 and 9 show the wall-layer structure of the PCF cell wall obtained by AFM. From Figure 9A, the wall structure of the cell wall of a poplar catkin fiber can be seen. It can be clearly seen from Figure 9 that the cell wall of PCF has three layers, and the cell wall thickness was about $0.5 \mu \mathrm{m}$. The cell wall has three layers, including a primary wall, secondary wall, and epidermis layer. The primary wall and epidermal layer were relatively thin, the secondary wall was relatively thick, and the connection between the primary wall and epidermal layer with the secondary wall was the darkest. In the modulus image, cellulose microfibril is the bright part, and the interstitial space between the non-cellulose polysaccharide matrix and microfibril is the dark part, because this matrix is significantly less elastic and harder than the microfibril [29,45-48]. Chen et al. [17,25] concluded that from the inside of the cell wall to the outside of the cell wall, the density of cellulose microfibril aggregates was unevenly distributed. The test data indicated that the number of cellulose microfibrillar aggregates in the boundary position was significantly higher than that inside the three layers, and the arrangement was dense.
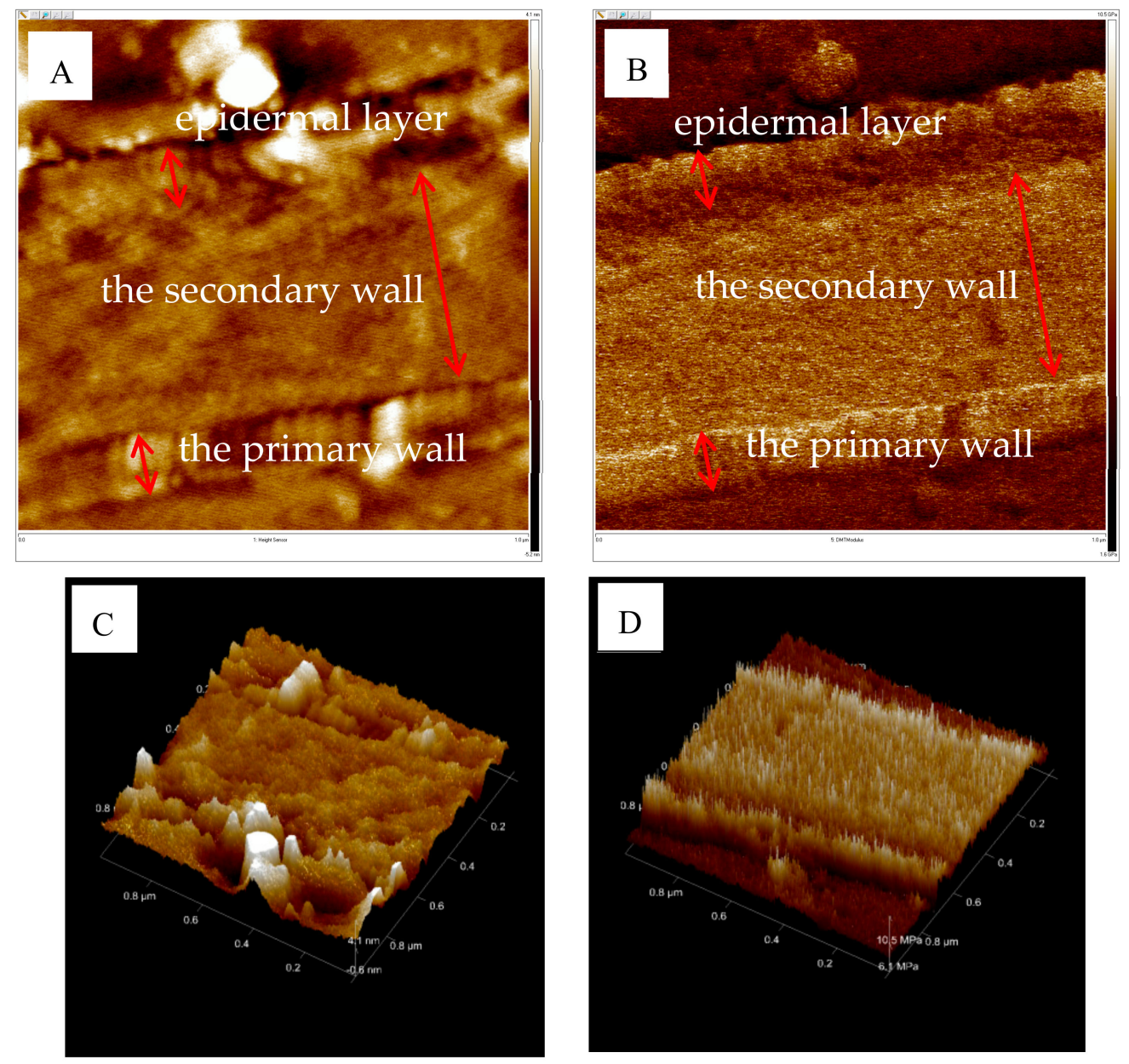

Figure 9. AFM observation of the cell wall structure of a poplar catkin fiber (cross-section; (A) height image; (B) modulus image; (C) 3D height image; (D) 3D modulus image).

\subsection{FT-IR Analysis}

The FT-IR spectrum (Figure 10) of untreated PCFs indicated that there were strong characteristic peaks of cellulose near 1040 and $3430 \mathrm{~cm}^{-1}$, indicating that PCFs had a similarly high cellulose content to kapok and cotton fibers. The absorption peaks of aromatic ring skeleton groups, unconjugated carboxyl groups, and other vibrational groups of lignin occurred between 1500 and $1750 \mathrm{~cm}^{-1}$. The peaks of cellulose absorption characteristics, i.e., free $\mathrm{O}-\mathrm{H}$ stretching vibrations of $-\mathrm{OH}$ groups, $\mathrm{C}-\mathrm{H}$ stretching vibrations of alkyl groups, $\mathrm{C}-\mathrm{H}$ bending vibrations, $\mathrm{C}-\mathrm{O}$ stretching vibrations, and $\mathrm{C}_{1}$ 
vibrations, appeared at 3430, 2850, 1380, 1040, and $900 \mathrm{~cm}^{-1}$, respectively, showing that celluloses also existed in PCFs. The existence of the absorption peak at $2350 \mathrm{~cm}^{-1}$ was mainly because of carbon dioxide in the air. The absorption peak at $2920 \mathrm{~cm}^{-1}$ was because of the $\mathrm{C}-\mathrm{H}$ stretching vibration of aliphatic groups from waxy layers, indicating that PCFs mainly consist of cellulose, hemicellulose, lignin, and a waxy surface.

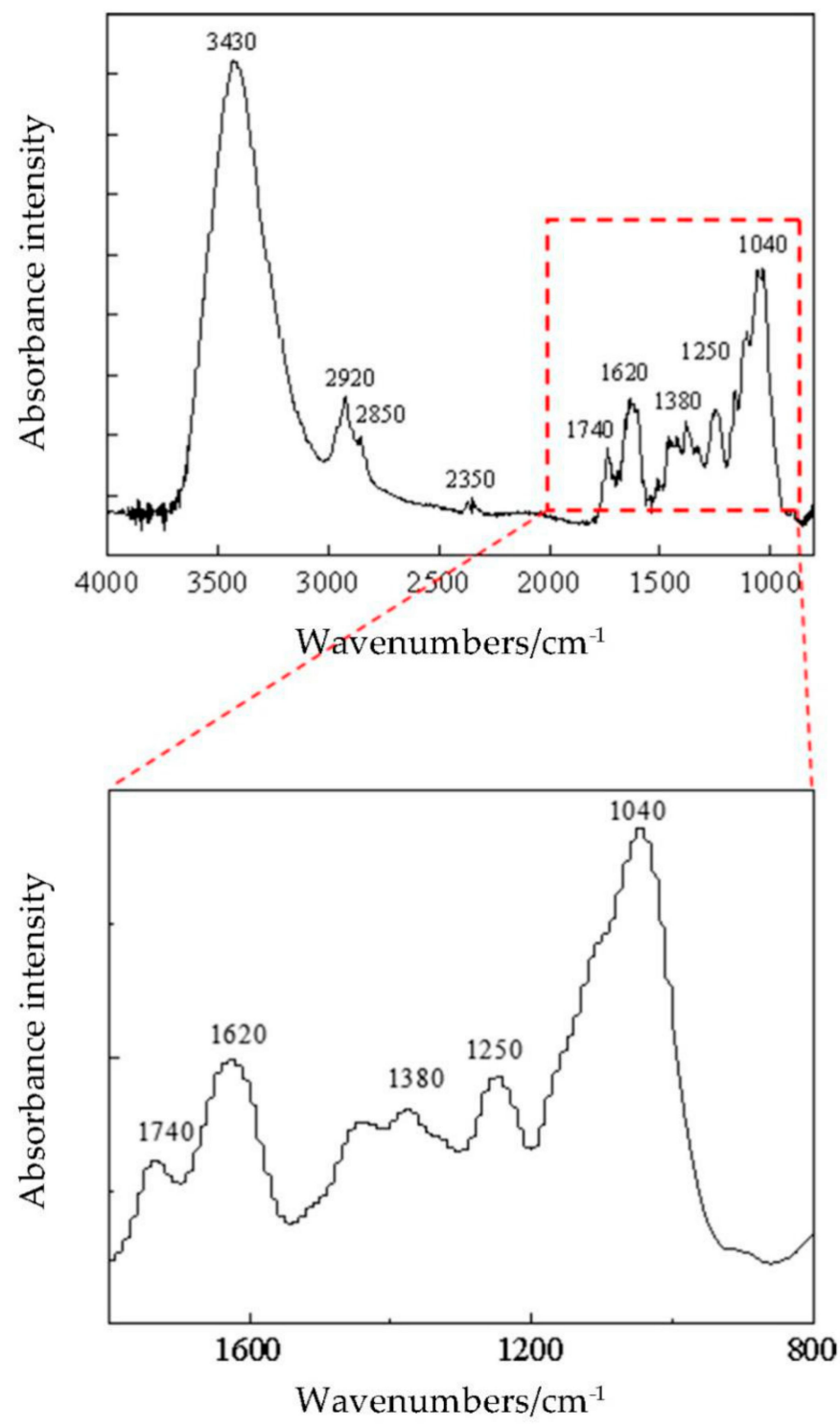

Figure 10. Fourier-transform infrared spectrogram and partial rendering of a poplar catkin fiber.

\subsection{In Situ Nanoindentation}

Because the $S_{2}$ layer was thicker than the other two layers and it was the main carrier of the mechanical properties of PCF, the nanoindentation test was mainly concentrated in this layer. The SEM image of the PCF cell wall cross-section, the nano-indentation image of the indent positions, and the typical load-displacement curve are shown in Figure 11A-C, respectively. The average reduced elastic modulus of the $\mathrm{S}_{2}$ layer was $5.28 \mathrm{GPa}$ and the hardness was $0.25 \mathrm{GPa}$, which was lower than that of softwood (6.55-27.5 GPa) and hardwood (16.9-24.6 GPa) [11], but higher than that of cotton fibers (4 GPa) [23] and kapok fibers (2 GPa) [41]. Huang et al. [49,50] found that the reduced elastic modulus of bamboo fiber cell walls in the transverse direction was $5.91 \mathrm{GPa}$, and in the longitudinal direction, was $17.6 \mathrm{GPa}$, and the hardness was $0.37 \mathrm{GPa}$. The samples were embedded in epoxy resin, which 
might result in undesirable chemical modifications caused by epoxy impregnation [50,51]. Therefore, the influence of epoxy resin, the interface between the fiber and resin, and the microfibril angle of the fiber on the nanomechanical properties of PCF will be evaluated in future work.
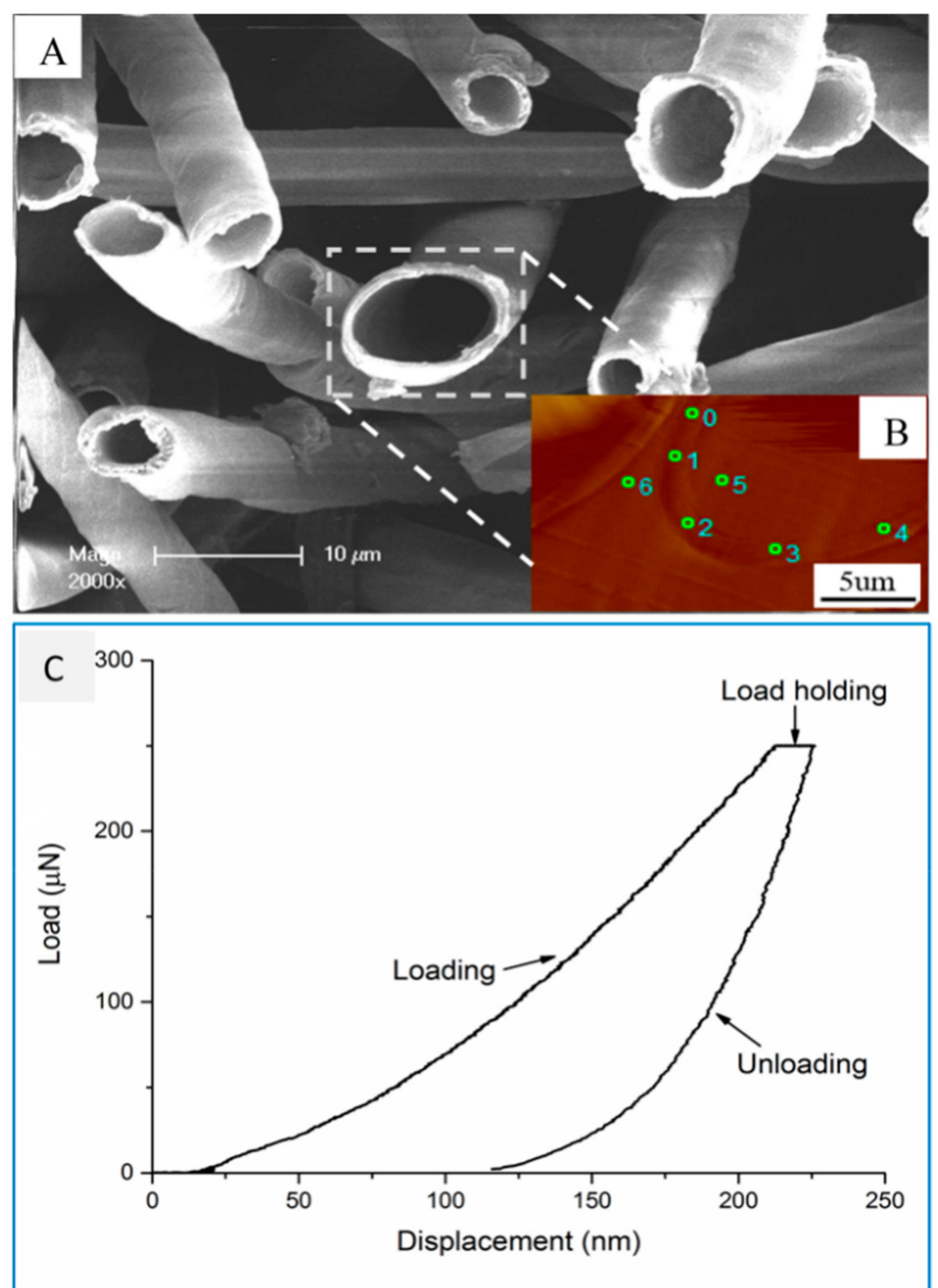

Figure 11. SEM image of the cross-section of poplar catkin fibers (A), inserted nano-indentation image of indent positions for the PCF cell wall by nanoindentation (B), and a typical nanoindentation load-displacement curve (C).

\section{Conclusions}

The microscopic morphology and mechanical properties of PCF cell walls were investigated. The PCFs mainly consisted of cellulose, hemicellulose, lignin, and a small wax layer. The PCFs were characterized as having a thin cell wall and large cavity, as well as a good hygroscopicity. After dewaxing treatment by chloroform, the PCF surface was uneven, and the wrinkle and roughness exhibited torsion. PCF cell walls were composed of a primary wall, secondary wall, and epidermis. The microfibril arrangements of primary walls and the epidermis were similar. The PCFs had a three-layer composite structure, and the $S_{2}$ layer was the thickest one. Cellulose nanocrystals (CNCs) or CNFs are mainly obtained by acid hydrolysis, alkali, tempo, or enzyme treatments. The outer layer of hemicellulose in PCFs is covered with wax and trace lignin. The lower relative crystallinity and loose structure make it easy to dissociate. Therefore, PCFs can be an excellent raw material for the preparation of CNCs or CNFs. 
Author Contributions: Conceptualization, H.W. and Y.W.; writing-original draft preparation, X.W., M.S. and Y.W.; investigation, X.W.; methodology, T.S. and H.C.; funding acquisition, H.W., J.Z. and Y.W.

Funding: We would like to thank the financial support provided by the Basic Scientific Research Funds of the International Center for Bamboo and Rattan (1632018016); Practical innovation training program for Nanjing Forestry University students (2018NFUSPITP643); and the Huzhou city, Zhejiang province, "Nan Taihu Lake elite plan" project ((2018 No.2).

Acknowledgments: The authors gratefully acknowledgement the strong support provided by International Center for Bamboo and Rattan and Nanjing Forestry University.

Conflicts of Interest: The authors declare no conflict of interest.

\section{References}

1. Kontturi, E.; Tammelin, T.; Oesterberg, M. Cellulose-model films and the fundamental approach. Chem. Soc. Rev. 2006, 35, 1287-1304. [CrossRef] [PubMed]

2. Ye, D.Y.; Huang, H.H.; Fu, H.Q. Advances in cellulose chemistry. J. Chem. Eng. 2006, 57, 1782-1791.

3. Chen, W.S.; Yu, H.P.; Lee, S.Y.; Wei, T.; Li, J.; Fan, Z. Nanocellulose: A promising nanomaterial for advanced electrochemical energy storage. R. Soc. Chem. 2018, 47, 2837-2872. [CrossRef] [PubMed]

4. Siró, I.; Plackett, D. Microfibrillated cellulose and new nanocomposite materials: A review. Cellulose 2010, 17, 459-494. [CrossRef]

5. Nogi, M.; Iwamoto, S.; Nakagaito, A.N.; Yano, H. Optically Transparent Nanofiber Paper. Adv. Mater. 2010, 21, 1595-1598. [CrossRef]

6. Wang, X.; Zhan, T.Y.; Liu, Y.; Shi, J.T.; Pan, B.; Zhang, Y.L.; Cai, L.P.; Shi, S.Q. Large-scale transparent wood for energy-saving building applications. ChemSusChem 2018, 11, 4086-4093. [CrossRef]

7. Minami, S.; Azuma, A. Various flying modes of wind-dispersal seeds. J. Theor. Biol. 2003, 225, 1-14. [CrossRef]

8. Wu, F.; Zou, Y.M.; Long, S.H. Advances in plant cell wall research. Hunan Agric. Sci. 2010, 5, $14-16$.

9. Zhang, X.X.; Li, Z.Q.; Yu, Y.; Wang, H.K. Characterizations of poplar catkin fibers and their potential for enzymatic hydrolysis. J. Wood Sci. 2018, 64, 458-462. [CrossRef]

10. Yin, C.Q.; Zhang, H.T. Morphological structure and application of poplar catkin fiber. Shandong Text. Econ. 2013, 37, 37-38.

11. Cheng, X.; Hao, H.Q.; Peng, L. Progress in cellulose synthesis in plant cell walls. Acta Bot. Trop. 2011, 19, 283-290.

12. Lu, Q.Q.; Liang, C.X. Composition of plant cell walls. World Biotechnol. 2016, 2, 302.

13. Fei, B.H.; Zhang, B.; Yu, Y. Study on mechanical properties of masson pine fiber. Chinese J. Papermaking 2006, $4,1-4$.

14. Wu, Y.; Wang, S.Q.; Zhou, D.G.; Xing, C.; Zhang, Y.; Pharr, G.M. Use of nanoindentation and SilviScan to determine the mechanical properties of ten hardwood species. Wood Fiber Sci. 2009, 44, 64-73.

15. Yu, Y.; Jiang, Z.H.; Fei, B.H. Review on the mechanics of tracheid cell wall. For. Sci. 2003, 39, $133-139$.

16. Yu, Y.; Jiang, Z.H.; Ren, H.Q. Study on the influence factors of longitudinal zero distance tensile strength of needle tracheid. Chin. J. Papermak. 2007, 22, 72-76.

17. Chen, H.; Tian, G.L.; Wu, Z.H.; Fei, B.H. Microfiber aggregates in pretreated bamboo fibers analyzed with Atomic Force Microscopy. Wood Fiber Sci. 2016, 48, 104-116.

18. Chen, H.; Zhang, W.F.; Wang, H.K.; Wu, Y.; Zhong, T.H.; Fei, B.H. Effect of alkali treatment on wettability and thermal stability of individual bamboo fibers. J. Wood Sci. 2018, 24, 333-347. [CrossRef]

19. Huang, C.X.; Ma, J.M.; Liang, C.; Li, X.; Yong, Q. Influence of sulfur dioxide-ethanol-water pretreatment on the physicochemical properties and enzymatic digestibility of bamboo residues. Bioresour. Technol. 2018, 263, 17-24. [CrossRef]

20. Huang, C.X.; Tang, S.; Zhang, W.Y.; Tao, Y.H.; Lai, C.H.; Li, X.; Yong, Q. Unveiling the structural properties of lignin-carbohydrate complexes in bamboo residues and its functionality as antioxidants and immunostimulants. ACS Sustain. Chem. Eng. 2018, 6, 12522-12531. [CrossRef]

21. Li, Z.Q.; Jiang, Z.H.; Fei, B.H.; Cai, Z.Y.; Pan, X.J. Comparison of bamboo green, timber and yellow in sulfite, sulfuric acid and sodium hydroxide pretreatments for enzymatic saccharification. Bioresour. Technol. 2014, 151, 91-99. [CrossRef] [PubMed] 
22. Ren, D.; Wang, H.K.; Yu, Z.X.; Wang, H.; Yu, Y. Mechanical imaging of bamboo fiber cell walls and their composites by means of peakforce quantitative nanomechanics (PQNM) technique. Holzforschung 2015, 69, 975-984. [CrossRef]

23. Xiao, H. Structure and Properties of Woody Cotton Fibers and Theirs Oakage and Buoyancy Characteristics of Aggregates. Ph.D. Thesis, Shanghai Donghua University, Shanghai, China, 2005.

24. Hao, Z.; Ying, S.; Xue, Z.; Pu, J.W. Efficient organic solvent system used to separate the cellulose and lignin of poplar. Int. J. Plant Res. 2014, 2, 1-4.

25. Chen, H.; Tian, G.L.; Fei, B.H. Arrangement of Cellulose Microfibrils in Primary Cell Wall of Moso Bamboo Fiber Studied with AFM. Sci. Silvae Sin. 2014, 50, 90-94.

26. Xiao, H. Basic structure and properties of kapok fiber. J. Text. 2005, 26, 4-6.

27. Fernandes, A.N.; Thomas, L.H.; Altaner, C.M.; Callow, P.; Forsythd, V.T.; Apperley, D.C.; Kennedy, C.J.; Jarvish, M.C. Nanostructure of cellulose microfibrils in spruce wood. Proc. Natl. Acad. Sci. USA 2011, 108, 784-793. [CrossRef]

28. Oliver, W.C.; Pharr, G.M. An improved technique for determining hardness and elastic modulus using load and displacement sensing indentation experiments. J. Mater. Res. 1992, 7, 1564-1583. [CrossRef]

29. Salmén, L.; Burgert, I. Cell wall features with regard to mechanical performance. A review cost action E35 2004-2008: Wood machining-micromechanics and fracture. Holzforschung 2009, 63, 121-129.

30. Burgert, I.; John, W.C. Dunlop micromechanics of cell wall smechanical integration of plant cells and plants. Signal. Commun. Plants 2011, 9, 7-52.

31. Himmel, M.E.; Ding, S.Y.; Johnson, D.K.; Adney, W.S.; Nimlos, M.R.; Brady, J.W.; Foust, T.D. Biomass recalcitrance: Engineering plants and enzymes for biofuels production. Science 2007, 315, 804-807. [CrossRef]

32. TAPPI standard T222 om-98. In Acid-Insoluble Lignin in Wood and Pulp; Technical Association of the Pulp and Paper Industry: Atlanta, GA, USA, 1998.

33. Woodward, J.; Hayes, M.K.; Lee, N.E. Hydrolysis of cellulose by saturating and non-saturating concentrations of cellulase-implications for synergism. Nat. Biotechnol. 1988, 6, 301-304. [CrossRef]

34. ASTM D1926-2000. In Standard Test Methods for Carboxyl Content of Cellulose; ASTM International: West Conshohocken, PA, USA, 2011.

35. ASTM D4988-96. In Standard Test Method for Determination of Alkalinity of Paper as Calcium Carbonate (Alkaline Reserve of Paper); ASTM International: West Conshohocken, PA, USA, 2001.

36. Rengasamy, R.S.; Das, D.; Karan, C.P. Study of oil sorption behavior of filled and structured fiber assemblies made from polypropylene, kapok and milkweed fibers. J. Hazard. Mater. 2011, 186, 526-532. [CrossRef] [PubMed]

37. Yuan, S.S. Preparation and Properties of Cotton Pulp Nano-Cellulose Blend Membrane. Ph.D. Thesis, Qingdao University of Science and Technology, Qingdao, China, 2016.

38. Schwanningera, M.; Rodriguesc, J.C.; Pereira, H.N. Nanocellulose: A promising nanomaterial for advanced electrochemical energy storage. Effects of short-time vibratory ball milling on the shape of FT-IR spectra of wood and cellulose. Vib. Spectrosc. 2004, 36, 23-40. [CrossRef]

39. Segal, L.; Creely, J.J.; Martin, A.E. An empirical method for estimating the degree of crystallinity of native cellulose using the X-Ray diffractometer. Text. Res. J. 1959, 29, 786-794. [CrossRef]

40. Jiang, Z.H.; Yu, W.J.; Yu, Y.L. Chemical composition Analysis and Surface performance characterization of Bamboo. J. Northeast For. Univ. 2006, 34, 1-2,6.

41. Qiu, J.; Du, G.B.; Bao, K.Y. Studies on chemical constituents and fiber Morphology of artificial cultivated wood. J. Southwest For. Univ. 2003, 23, 81-83.

42. Higuchi, T. Chemistry and biochemistry of bamboo. Bamboo J. 1987, 4, 132-145.

43. Wang, Y.P.; Gao, X.S. Comparison of structure and Properties between Natural Bamboo Fiber and Bamboo Pulp Viscose Fiber. Plant Fibers Prod. 2006, 28, 97-100.

44. Yu, Y.; Fei, B.H.; Zhang, B. Evaluation of wood tracheid longitudinal by zero-span stretching technique tensile strength. For. Sci. 2006, 42, 83-86.

45. Wang, X.; Chen, X.; Xie, X.; Cai, S.; Yuan, Z.; Li, Y. Multi-scale evaluation of the effect of phenol formaldehyde resin impregnation on the dimensional stability and mechanical properties of Pinus Massoniana Lamb. Forests 2019, 10, 646. [CrossRef] 
46. Wang, X.; Wang, S.; Xie, X.; Zhao, L.; Deng, Y.; Li, Y. Multi-scale evaluation of the effects of nanoclay on the mechanical properties of wood/phenol formaldehyde bondlines. Int. J. Adhes. Adhes. 2017, 74, 92-99. [CrossRef]

47. Wang, X.; Deng, Y.; Wang, S.; Liao, C.; Meng, Y.; Pham, T. Nanoscale Characterization of Reed Stalk Fiber Cell Walls. Bioresources 2013, 8, 1986-1996. [CrossRef]

48. Wang, X.; Li, Y.; Deng, Y.; Yu, W.; Xie, X.; Wang, S. Contributions of the basic chemical components to the mechanical behaviour of wood fiber cell walls evaluated by nanoindentation. BioResources 2016, 11, 6026-6039. [CrossRef]

49. Huang, C.; Wang, X.; Liang, C.; Jiang, X.; Yang, G.; Xu, J.; Yong, Q. A sustainable process for procuring biologically active fractions of high-purity xylooligosaccharides and water-soluble lignin from Moso bamboo prehydrolyzate. Biotechnol. Biofuels 2019, 12, 189. [CrossRef]

50. Huang, C.; Sun, R.; Chang, H.M.; Yong, Q.; Jameel, H.; Phillips, R. Production of Dissolving Grade Pulp from Tobacco Stalk Through SO2-ethanol-water Fractionation, Alkaline Extraction, and Bleaching Processes. BioResources 2019, 14, 5544-5558.

51. Yan, X.; Wang, L.; Qian, X. Effect of High-Temperature Calcined Wheat Straw Powder after Lignin Removal on Properties of Waterborne Wood Coatings. Coatings 2019, 9, 444. [CrossRef]

(C) 2019 by the authors. Licensee MDPI, Basel, Switzerland. This article is an open access article distributed under the terms and conditions of the Creative Commons Attribution (CC BY) license (http://creativecommons.org/licenses/by/4.0/). 